\title{
PENGARUH REWARD TERHADAP KEPUASAN KERJA KARYAWAN PDAM MAGETAN
}

\author{
Lailatul Muqoyyaroh \\ Prodi Pendidikan Ekonomi FKIP UNIVERSITAS PGRI MADIUN \\ lailatulmukhoyyaroh@gmail.com
}

\begin{abstract}
This research has purpose to know giving reward at PDAM Magetan, to know employee job satisfaction at PDAM Magetan, and to know influence of reward to employee job satisfaction at PDAM Magetan. Sampling technique in this research using simple random sampling technique taken 66 employees at PDAM Magetan. Data were taken by questionnaire, observation and documentation. The analysis was processed by SPSS version 16.0 using simple linear regression with test test and test hypothesis test. The results showed that the result of Simple Linear Regression Test is $Y=13.054+$ 0.496 , it means that if the variable of customer satisfaction is constant or constant, then the amount of job satisfaction of employee is 13,054. The result of Coefficient of Determination $(R \wedge 2)$ is known 0,879 indicates that $87 \%$ variable of employee job satisfaction influenced by reward, while the rest $13 \%$ influenced by other variable. Furthermore, the result of t test obtained t_hitung value is 21,549 while t_tabel equal to 1,668. This means that the value of $t$ _count $>t_{-}$tabel $(21,549>1,668)$ so it can be concluded that Ho is rejected and Ha accepted, it means there is influence between Reward on Job Satisfaction Employees At PDAM Magetan.
\end{abstract}

Keywords : Reward, Employee Job Satisfaction

\begin{abstract}
Abstrak
Penelitian ini mempunyai tujuan untuk mengetahui pemberian reward pada PDAM Magetan, untuk mengetahui kepuasan kerja karyawan pada PDAM Magetan, dan untuk mengetahui pengaruh reward terhadap kepuasan kerja karyawan pada PDAM Magetan. Teknik pengambilan sampel dalam penelitian ini menggunakan teknik simple random sampling yang diambil 66 orang karyawan pada PDAM Magetan. Data diambil dengan angket, observasi dan dokumentasi. Analisa diolah dengan program SPSS versi 16.0 menggunakan regresi linear sederhana dengan uji hipotesis uji determinasi dan uji t. Hasil Penelitian menunjukkan bahwa hasil dari Uji Regresi Linier Sederhana adalah Y = $13.054+0,496$, artinya apabila variabel kepuasan pelanggan tetap atau constant, maka besarnya kepuasan kerja karyawan adalah 13,054. Hasil dari Koefisien Determinasi $\left(K^{2}\right)$ diketahui 0,879 menunjukkan bahwa sebesar $87 \%$ variabel kepuasan kerja karyawan dipengaruhi reward, sedangkan sisanya $13 \%$ dipengaruhi oleh variabel lain. Selanjutnya hasil dari Uji t diperoleh nilai $t_{h t}$ adalah 21,549 sedangkan $t_{t} \quad$ sebesar 1,668. Hal ini berarti bahwa nilai $t_{h t}>t_{t_{i}} \quad(21,549 \geq 1,668)$ sehingga dapat disimpulkan bahwa Ho ditolak dan Ha diterima, artinya ada pengaruh antara Reward terhadap Kepuasan Kerja Karyawan Pada PDAM Magetan.
\end{abstract}

Kata Kunci : Reward, Kepuasan Kerja Karyawan 


\section{PENDAHULUAN}

Sumber daya manusia merupakan aset penting dalam suatu organisasi, karena merupakan sumber yang mengendalikan organisasi serta mempertahankan dan mengembangkan organisasi dalam menghadapi berbagai tuntutan zaman, oleh karena itu sumber daya manusia harus diperhatikan, dijaga dan dikembangkan. Sumber daya manusia perlu dikembangkan secara terus menerus agar diperoleh sumber daya manusia yang bermutu dalam arti sebenarnya yaitu pekerjaan yang dilaksanakan akan menghasilkan sesuatu yang dikehendaki. Berhadapan dengan usaha peningkatan kinerja karyawan, salah satu permasalahan dasar adalah bagaimana sebenarnya meningkatkan kepuasan kerja karyawan.

Kepuasan kerja merupakan salah satu faktor yang sangat penting untuk mendapatkan hasil yang optimal. Ketika seseorang merasakan kepuasan dalam bekerja, ia akan berusaha semaksimal mungkin dengan segenap kemampuan yang dimilikinya untuk menyelesaikan tugas pekerjaannya. Pada dasarnya kepuasan kerja merupakan hal yang bersifat individu. Setiap individu memiliki tingkat kepuasan yang berbeda-beda sesuai dengan sistem nilainilai yang berlaku pada dirinya. Ini disebabkan karena adanya perbedaan pada masing-masing individu (Mila Badriyah, 2015: 227)

Penghargaan/reward yang merupakan salah satu faktor penentu kepuasan kerja karyawan. Perusahaan perlu memberikan perhatian khusus terhadap kepuasan kerja karyawan dengan cara memberikan reward (hadiah, imbalan, dan promosi jabatan) kepada karyawannya. Reward di berikan perusahaan kepada karyawan bertujuan untuk mneingkatkan kepuasan kerja karyawan.

Menurut Mahsun (2006: 112), pada dasarnya ada dua tipe reward:

1) Social Reward adalah pujian dan pengakuan diri dari dalam dan luar organisasi, yang merupakan faktor extrinsik reward yang diperoleh dari lingkungannya, seperti financial materi, dan piagam penghargaan.

2) Psychic Reward datang dari self esteem (berkaitan dengan harga diri), selfsatisfaction (kepuasan diri) dan kebanggaan atas hasil yang dicapai, psychic reward adalah instrinsic reward yang datang dari dalam diri seseorang, seperti pujian, sanjungan, dan ucapan selamat yang dirasakan pegawai sebagian bentuk pengakuan terhadap dirinya dan mendatangkan kepuasan bagi dirinya sendiri

Menurut Nugroho (2006: 5) dalam Triyanto ( 2014: 30) tujuan utama dari program reward adalah:

1. Menarik orang yang memiliki kualifikasi untuk bergabung dengan organisasi.

2. Mempertahankan karyawan agar terus datang untuk bekerja.

3. Mendorong karyawan untuk mencapai tingkat kinerja yang tinggi.

Menurut Winardi (2004: 67), bentuk bentuk reward atau insentif dapat diklasifikasikan sebagai berikut :

1. Material berupa gaji/upah.

2. Imbalan diluar gaji.

3. Penghargaan sosial.

4. Tugas itu sendiri.

5. Diterapkan sendiri.

Keith Davis (1985: 96) dalam Anwar M. (2015: 117) mengemukakan bahwa "job satisfaction is the favorabieness or unfavorableness with employees view their work". (kepuasan kerja adalah perasaan menyokong atau tidak menyokong yang dialami pegawai dalam bekerja).

Penelitian yang dilakukan oleh Caugemi dan Claypool (dalam Edy Sutrisno, 2011: 78-79), menemukan bahwa hal-hal yang menyebabkan rasa puas adalah: 1) Prestasi 2) Penghargaan 3) Kenaikan jabatan 4) Pujian. Adapun faktor-faktor yang menyebabkan ketidakpuasan kerja adalah: 1) Kebijaksanaan perusahaan 2) Supervisor 3) Kondisi kerja 4) Gaji.

Menurut Spector (Yuwono, 2005: 69) (dalam Mila Badriyah, 2015: 241) mendefinisikan kepuasan sebagai cluster 
perasaan evaliatif tentang pekerjaan. Ia mengidentifikasikan indikator kepuasan kerja dari sembilan aspek, yaitu:

1. Upah, jumlah dan rasa keadilannya

2. Promosi, peluang dan rasa keadilan untuk mendapatkan promosi

3. Supervise, keadilan dan kompetensi penugasan manajerial oleh penyedia

4. Benefit, asuransi, liburan dan bentuk fasilitas yang lain

5. Contigent rewards, rasa hormat diakui dan diberikan apresiasi

6. Operating procedures, kebijakan, prosedur dan aturan

7. Co-workers, rekan kerja yang menyenangkan dan kompeten

8. Nature of work, tugas itu didapat dinikmati atau tidak

9. Communication, berbagai informasi di dalam organisasi, baik verbal maupun nonverbal.

Menurut Veithzal dan Ella (2009: 860-

861) Kepuasan kerja adalah bagaimana orang merasakan pekerjaan dan aspekaspeknya. Ada beberapa alasan mengapa perusahaan harus benar-benar memperhatikan kepuasan kerja, yang dapat dikategorikan sesuai dengan fokus karyawan atau perusahaan, yaitu:

1. Manusia berhak diberlakukan dengan adil dan hormat pendapat ini menurut perspektif kemanusiaan. Kepuasan kerja meruakan perluasan refleksi perlakuan yang baik. Penting juga memperhatikan indicator emosional atau kesehatan psikologis.

2. Perspektif kemanfaatan, bahwa kepuasan kerja dapat menciptakan perilaku yang mempengaruhi fungsifungsi perusahaan. Perbedaan kepuasan kerja antara unit-unit organisasi dapat mendiagnosis potensi personal.

Menurut Wexley dan Yuki (1977)

(Dalam Mila Badriyah, 2015: 237) teori tentang kepuasan kerja terdiri atas tiga macam, yaitu:

1. Teori Perbandingan Intrapersonal (Discrepancy Theory). Kepuasan dan ketidakpuasan individu merupakan hasil perbandingan atau kesenjangan yang dilakukan oleh diri sendiri terhadap berbagai hal yang sudah diperolehnya dari pekerjaan dan menjadi harapannya. Kepuasan akan dirasakn oleh individu tersebut apabila perbedaan atau kesenjangan antara standar pribadi individu dan sesuatu yang diperoleh dari pekerjaannya kecil. Sebaliknya, ketidakpuasan akan dirasakan oleh individu apabila perbedaan atau kesenjangan antara standar pribadi individu dengan sesuatu yang diperoleh dari pekerjaan besar.

2. Teori keadilan (Equity Theory). Tingkat kepuasan seseorang bergantung pada caranya merasakan adanya keadilan atau tidak atas suatu situasi. Perasaan equity atau inequity terhadap suatu situasi diperoleh seseorang dengan cara membandingkan dirinya dengan orang lain yang sekelas, sekantor ataupun di tempat lain.

3. Teori Dua-Faktor (Two Factor Theory). Prinsip teori ini adalah kepuasan dan ketidakpuasan kerja merupakan dua hal yang berbeda. Menurut teori ini, karakteristik pekerjaan dapat dikelompokkan menjadi dua kategori yaitu: dissatisfier (hygiene factors) dan satisfier (motivators).

\section{METODE PENELITIAN}

Penelitian dilaksanakan di Kantor PDAM Kabupaten Magetan yang beralamat di Jalan Tripandita Nomer 5 Kabupaten Magetan. Alasan pemilihan tempat tersebut dikarenakan belum pernah dilakukan penelitian tentang pengaruh pemberian reward terhadap kepuasan kerja karyawan di kantor PDAM Magetan, Pihak PDAM Kabupaten Magetan mudah untuk koordinasi dan pro aktif dalam kegiatan penelitian ini.

Desain penelitian yang digunakan dalam penelitian ini adalah penelitian deskriptif. "Desain penelitian deskriptif bertujuan untuk mendeskripsikan sifat atau karakteristik dari suatu gejala, peristiwa, kejadian yang terjai saat ini" Juliansyah Noor (2013: 111). 
Populasi dalam penelitian ini adalah semua karyawan Kantor "PDAM Magetan" yang seluruhnya berjumlah 221 .

Pengambilan sampel dilakukan dengan teknik Simpel Random Sampling. Teknik pengumpulan data yang digunakan adalah :

1. Angket

Dalam mengambil data variabel Reward (X) dan variabel Kepuasan Kerja Karyawan. Jumlah soal dalam angket ini adalah 28 soal pernyataan, yang terbagi dalam dua variabel yang akan diteliti. 10 soal untuk variabel Reward (X) dan 18 soal untuk variabel Kepuasan Kerja (Y). Yang menjadi responden dalam teknik pengumpulan data dengan angket pada penelitian ini adalah karyawan PDAM Magetan sebanyak 66 karyawan.

2. Observasi
Dalam penelitian ini metode observasi dilakukan dengan cara peninjauan peninjauan secara langsung ke objek penelitian yaitu Kantor "PDAM Magetan" untuk memperoleh data yang diperlukan untk kelancaran penyusunan penelitian yang berkaitan dengan judul yang diteliti.

3. Dokumentasi

Metode ini digunakan untuk memperoleh data-data yang peneliti butuhkan dengan melalui catatan-catatan yang ada atau dokumen-dokumen yang ada berupa foto dari karyawan dalam melayani nasabahnya.

1. Uji Prasarat atau Instrumen

a. Uji Validitas

Dalam uji validitas digunakan korelasi product moment.

b. Uji Reliabilitas

Uji reliabilitas yang digunakan dalam penelitian ini menggunakan metode Alpha Cronbach.

Menurut Syofiyan Siregar (2014:89) Alpha Cronbach adalah "metode yang digunakan untuk menghitung reabilitas suatu tes yang tidak mempunyai pilihan "benar" atau "salah" maupun "ya" atau "tidak", melainkan digunakan untuk menghitung reabilitas suatu tes yang mengukur sikap atau perilaku".

2. Uji Asumsi Klasik

Menurut Imam Gunawan (2016: 92) Uji Asumsi Klasik merupakan "uji data yang digunakan untuk mengetahui apakah data penelitian memenuhi syarat untuk dianalisis lebih lanjut, guna menjawab hipotesis penelitian". Uji Asumsi Klasik dalam penelitian ini menggunakan Uji Normalitas.

Uji normalitas dilakukan dengan uji nilai Kolmogorov Smirnov dapat menggunakan program analisis statistik IBM SPSS Statistics 16. "Pada uji statistic One Sample KolmogorovSmirnovTest, jika di dapat nilai signifikan $>0,05$, maka dapat disimpulkan bahwa data terdistribusi normal secara multivariate" (Latan dan Temalagi, 2013: 81).

3. Uji Hipotesis atau Analisis Data

Untuk uji hipotesis menggunakan teknik analisis regresi linier sederhana menggunakan koefisien determinan dan uji t. Koefisien determinasi digunakan untuk menguji pengaruh antara variabel satu dengan yang lain. Variabel yang dimaksud adalah variabel independen yaitu Reward (X) dan variabel dependen yaitu Kepuasan Kerja Karyawan (Y). Sedangkan uji t untuk mengetahui apakah variabel bebas secara individu mempunyai pengaruh yang signifikan terhadap variabel terikat.

\section{HASIL DAN PEMBAHASAN}

Dideskripsikan bahwa Reward dengan jumlah data (N) sebanyak 66 responden mempunyai deskripsi data sebagai berikut: (a) Jumlah skor total sebesar 2898; ((b) Nilai rata-rata hitung (mean) 43,91; (c) Median sebesar 44,00; (d) Modus sebesar 44,00; (e) Standar Deviasi sebesar 2,766; (f) Nilai minimum 37; (g) Nilai maximum 49.

hasil analisis reward pada karyawan PDAM Magetan dapat diketahui hasil 
angket dari 66 karyawan yang berada di atas rata-rata sebanyak 40 karyawan atau sebesar $60 \%$, sedangkan yang di bawah rata-rata sebanyak 26 karyawan atau sebesar 40.

Dideskripsikan bahwa Kepuasan kerja Karyawan dengan jumlah data $(\mathrm{N})$ sebanyak 66 responden mempunyai deskripsi data sebagai berikut: (a) Jumlah skor total sebesar 5225; (b) Nilai rata-rata hitung (mean) 79,17; (c) Median sebesar 80,00; (d) Modus sebesar 80,00; (e) Standar Deviasi sebesar 4,443; (f) Nilai minimum 67; (g) Nilai maximum 85.

Hasil analisis deskriptif kepuasan kerja karyawan pada karyawan PDAM Magetan dapat diketahui hasil angket dari 66 karyawan yang berada di atas rata-rata sebanyak 39 karyawan atau sebesar 59\%, sedangkan yang di bawah rata-rata sebanyak 28 karyawan atau sebesar $41 \%$.

\section{Hasil Uji Validitas}

Hasil dari uji validitas angket Reward di uji kepada nasabah di PT. Bank Jateng KCP Cepu berjumlah 20 responden. Dari 10 soal Reward yang di uji hasilnya semua valid. Hasil dari uji validitas angket Kepuasam Kerja Karyawan di uji kepada karyawan PDAM Magetan berjumlah 20 responden. Dari 18 soal Kepuasan Kerja Karyawan yang di uji hasilnya semua valid ( koefisien di atas 0,4227) dapat dipergunakan oleh peneliti sebagai instrumen penelitian.

\section{Hasil Uji Reliabilitas}

Uji Reliabilitas pada penelitian ini dilakukan dengan menggunakan rumus alpha cronbach. Syofian Siregar (2014: 90), "kriteria suatu instrumen penelitian dikatakan reliabel dengan menggunakan teknik Alpha Cronbach bila koefisien reliabilitas $\left(r_{11}\right)>0,6$ ". Hasil uji reliabilitas variabel Reward dan Kepuasan Kerja Karyawan adalah 0,695 dan 0,836 maka semua dinyatakan reliabel.

\section{Hasil Uji Asumsi Klasik}

Uji Normalitas bertujuan untuk menguji apakah dalam model regresi variabel pengganggu atau residu memiliki distribusi normal. Apabila data berdistribusi normal, maka dapat digunakan uji statistik berjenis parametrik. Syarat analisis parametrik yaitu distribusi data harus normal. Pengujian menggunakan uji Kolmogorov-Smirnov (Analisis Explore) untuk mengetahui apakah distribusi data pada tiap-tiap variabel normal atau tidak. Hasil uji normalitas yang terdapat di atas bahwa nilai Assymp Sig sebesar 0,415 lebih besar dari 0.05 , dengan demikian dapat disimpulkan bahwa data yang akan dianalisis terdistribusi normal.

\section{Uji Regresi Linier Sederhana}

Uji Regresi Linier sederhana diperoleh persamaan $\mathrm{Y}=13,054+0,496$. Konstanta sama dengan 13,054, artinya apabila variabel Reward bernilai tetap atau konstant, maka besarnya kepuasan kerja karyawan adalah 9,311..

\section{Koefisien Determinasi (R-Square)}

Dari hasil pengolahan data dengan menggunakan program SPSS versi 16.0 dapat diketahui bahwa koefisien determinasi (R-Square) yang diperoleh sebesar 0,879. Yang artinya, Reward berpengaruh terhadap Kepuasan Kerja Karyawan pada PDAM Magetan sebesar $87 \%$ sedangkan sisanya sebesar $13 \%$ dipengaruhi oleh faktor lain yang tidak diteliti.

\section{Uji T}

Dari hasil perhitungan uji t diperoleh nilai $t_{\text {hitung }}$ sebesar 21,549 sedangkan $t_{\text {tabel }}$ 1,668, dilain pihak nilai $\mathrm{Sig}_{\text {hit }}$ adalah 0,000 sedangkan $\mathrm{Sig}_{\text {prob }} 0,05$. Hal ini berarti bahwa nilai $\mathrm{t}_{\text {hitung }} \geq \mathrm{t}_{\text {tabel }}(21,549 \geq 1,668)$ atau $\operatorname{Sig}_{\text {hit }} \leq \operatorname{Sig}_{\text {prob }}(0,000 \leq 0,05)$. Atas dasar uji t tersebut dapat disimpulkan bahwa HO ditolak dan Ha diterima,yang berarti ada beda pengaruh antara reward terhadap kepuasan kerja karyawan PDAM Magetan.

\section{PENUTUP}

Simpulan

Berdasarkan hasil analisis data dan pembahasan yang telah dilakukan pada bab sebelumnya, maka dapat disimpulkan 
sebagai berikut :

1. Reward yang diberikan perusahan pada karyawan PDAM Magetan cukup baik. Dari hasil observasi tersebut dihasilkan nilai rata-rata sebanyak 43,91, sehingga diperoleh nilai yang berada di atas ratarata sebanyak 40 karyawan atau sebesar $60 \%$, sedangkan yang di bawah rata-rata sebanyak 26 karyawan atau sebesar $40 \%$.

2. Kepuasan kerja karyawan pada PDAM Magetan adalah cukup baik. Dari hasil observasi tersebut dihasilkan nilai ratarata sebanyak 79,17 , sehingga sehingga diperoleh nilai yang berada di atas ratarata sebanyak 39 karyawan atu sebesar $59 \%$, sedangkan yang di bawah rata-rata sebanyak 29 karyawan atau sebesar $41 \%$

3. Pemberian reward mempunyai pengaruh terhadap kepuasan kerja karyawan pada PDAM Magetan. Terbukti dari hasil analisis melalui:

a. Uji Regresi Linier. Dari hasil Uji Regresi Linier Sederhana dapat diperoleh $\mathrm{Y}=13,054+0,496$ yang artinya konstanta sama dengan 13,054, artinya apabila variabel kepuasan pelanggan tetap atau constant, maka besarnya kepuasan kerja karyawan adalah 13,054. Sehingga dapat disimpulkan bahwa Ho ditolak dan $\mathrm{Ha}$ diterima, yang berarti ada pengaruh yang signifikan antara reward terhadap Kepuasan kerja karyawan.

b. Koefisien Deteminasi yang digunakan untuk mengetahui seberapa besar prosentase reward terhadap kepuasan kerja karyawan. Diketahui $\mathrm{R}^{2}$ adalah 0,879. Artinya pengaruh dari reward terhadap kepuasan kerja karyawan pada PDAM Magetan yaitu 87\%, sedangkan sisanya $13 \%$ dipengaruhi oleh faktor lain.

a. Uji $\mathrm{T}$ diperoleh ilai $\mathrm{t}_{\text {hitung }}$ sebesar 21,549 sedangkan nilai $t_{\text {tabel }}$ sebesar 0,2387 dilain pihak nilai Sighit $_{\text {adalah }}$ 0,000 sedangkan $\mathrm{Sig}_{\text {prob }}$ 0,05. Hal ini berarti bahwa nilai $t_{\text {hitung }} \geq \mathrm{t}_{\text {tabel }}$ $(21,549 \geq 2,387)$ atau $\operatorname{Sig}_{\text {hit }} \leq \operatorname{Sig}_{\text {prob }}$
$(0,000 \leq 0,05)$. Atas dasar uji $\mathrm{t}$ tersebut dapat disimpulkan bahwa $\mathrm{HO}$ ditolak dan $\mathrm{Ha}$ diterima,yang berarti ada beda pengaruh antara reward terhadap kepuasan kerja karyawan PDAM Magetan.

\section{Saran}

Berdasarkan kesimpulan yang diperoleh didalam penelitian, maka peneliti mengajukan saran kepada PT. Bank Jateng KCP Cepu dan bagi Peneliti selanjutya sebagai berikut :

1. Bagi Karyawan PDAM Magetan

a. Dengan adanya penelitian ini diharapkan dapat memotivasi karyawan untuk meningkatkan hasil kinerjannya. Kinerja karyawan yang baik akan memberikan kepuasan pada perusahaan, sehingga perusahaan dapat memberikan reward yang sesuai untuk karyawannya

b. Diharapkan dengan adanya penelitian ini dapat memberikan masukan bagi PDAM Magetan untuk meningkatkan kinerja karyawannya asalah satunya dengan memberikan reward sehingga dapat memberikan kepuasan kerja pada perusahaan.

2. Bagi Peneliti Selanjutnya

a. Penelitian ini diharapkan dapat menyelesaikan permasalahan yang ada di PDAM Magetan yang berkaitan dengan pemberian reward agar dapat meningkatkan kepuasan kerja karyawan. Dengan adanya reward yang baik, maka dapat meningkatkan kepuasan kerja karyawan.

b. Diharapkan dengan adanya penelitian ini peneliti mampu mampu menerapkan ilmu yang didapatkan dalam penelitian dan peneliti dapat menambah variabel bebas (X), karena selain reward masih banyak faktor-faktor lain yang dapat mempengaruhi kepuasan kerja karyawan pada PDAM Magetan. 
c. Dengan adanya penelitian ini diharapkan peneliti dapat mengetahui dan meningkatkan pemberian reward yang diterapkan di kantor PDAM Magetan.

3. Bagi UNIPMA MADIUN

Dengan penelitian ini diharapkan dapat memperoleh wawasan dan pengetahuan yang luas serta dapat dijadikan bahan referens bagi peneliti selanjutnya di perpustakaan.

\section{DAFTAR PUSTAKA}

Badriyah, M. (2015). Manajemen Sumber Daya Manusia. Bandung: CV Pustaka Setia.

Ella, J \& Rivai, V. (2009). Manajemen Sumber Daya Manusia Untuk Perusahaan. Jakarta: PT Raja Grafindo Persada.

Gunawan, I. (2016). Pengantar Statistika Inferensial. Jakarta: PT Raja Grafindo Persada.

Latan dan Temalagi. 2013. Analisis Multivariate. Alfabeta.
Mahsun, M. (2006) . Pengukuran Kinerja Sektor Publik. Yogyakarta: BPFE.

Mangkunegara, P. A. (2015). Manajemen Sumber Daya Perusahaan. Bandung: PT Remaja Rosdakarya.

Noor, J. (2013). Metodologi Penelitian (Skripsi, Tesis, Disertasi, \& Karya Ilmiah. Jakarta: Kencana.

Triyanto, A. \& Sudarwati (2014). Pengaruh Kompetensi dan Penghargaan Terhadap Motivasi Kerja Karyawan PT KAI di STASIUN SRAGEN. Jurnal Paradigma. 12 (01), 30.

Winardi. (2004). Motivasi dan pemotivasian dalam Manajemen. Jakarta: PT Raja Grafindo Persada.

Siregar, S. (2014). Statistik Parametik untuk Penelitian Kuantitatif; Dilengkapi dengan Perhitungan Manual dan Aplikasi SPSS Versi 17. Jakarta: Bumi Aksara.

Sutrisno, E. (2011). Manajemen Sumber Daya Manusia. Jakarta: Kencana. 